\title{
An Ionic Liquid-based Microextraction Method for Ultra-High Preconcentration of Paraquat Traces in Water Samples Prior to HPLC Determination
}

\author{
Takuya НАмамото ${ }^{* * * \dagger}$ and Shoichi KATSUTA ${ }^{* \dagger}$ \\ *Department of Chemistry, Graduate School of Science, Chiba University, 1-33 Yayoi-cho, Inage, Chiba 263-8522, \\ Japan \\ **Forensic Science Laboratory, Chiba Prefectural Police Headquarters, 1-71-1 Chuo-ko, Chuo, Chiba 260-0024, \\ Japan
}

\begin{abstract}
An ionic liquid (IL)-based microextraction method was developed for the preconcentration of paraquat traces in water samples prior to HPLC determination. On the basis of the relationship between the aqueous solubility and the extractability of known ILs, 1-ethyl-3-methylimidazolium bis(nonafluorobutanesulfonyl)amide ([EMIm][ $\left.\mathrm{NNf}_{2}\right]$ ) was selected as the extractant for paraquat. The distribution ratio of paraquat dication in the $\left[\right.$ EMIm] $\left[\mathrm{NNf}_{2}\right] /$ water biphasic system was theoretically estimated to be nearly $10^{8}$ at its maximum level, indicating that [EMIm] $\left[\mathrm{NNf}_{2}\right]$ was suitable for the ultra-high preconcentration (a maximum of $10^{6}$-fold concentration) of paraquat with a quantitative recovery (more than $99 \%$ ). The extraction procedure could be performed easily and quickly following the in situ solvent formation microextraction technique, and the paraquat traces in the IL phase could be determined by hydrophilic interaction chromatography with good detection limits and linearity ranges $\left(0.16\right.$ and $1-50 \mathrm{ng} \mathrm{mL}^{-1}$ for paraquat, respectively). The combined method was successfully applied to four real environmental water samples spiked with paraquat and its analog, diquat at $5.0 \mathrm{ng} \mathrm{mL} \mathrm{mL}^{-1}$.
\end{abstract}

Keywords Ionic liquid, in situ solvent formation microextraction, paraquat, HILIC

(Received August 3, 2018; Accepted September 3, 2018; Advance Publication Released Online by J-STAGE September 14, 2018)

\section{Introduction}

$1,1^{\prime}$-Dimethyl-4, $4^{\prime}$-bipyridinium dication (paraquat, $[\mathrm{PQ}]^{2+}$ ) is a well-known toxic herbicide that is frequently inspected in the analysis of toxicants. ${ }^{1,2}$ The analysis of $[\mathrm{PQ}]^{2+}$ in water samples has often been performed using solid phase extraction (SPE) for the pretreatment step and high-performance liquid chromatography (HPLC), including hyphenated techniques, for the instrumental analysis step. ${ }^{3-7}$ Such analysis normally requires preconcentration due to the low $[\mathrm{PQ}]^{2+}$ concentration in water samples. However, the SPE method is somewhat timeconsuming in terms of the preconcentration procedure. ${ }^{3,5}$ In addition, a satisfactory recovery in the microextraction of $[\mathrm{PQ}]^{2+}$ is yet to be achieved, ${ }^{8}$ even though this has been attempted by performing the microextraction after the transformation of $[\mathrm{PQ}]^{2+}$ to $1,1^{\prime}$-dimethyl-4,4'-bipiperidyl (electron neutral molecule) through the reduction of the pyridine rings. ${ }^{9}$

Recently, ionic liquids (ILs) have attracted considerable attention as novel extraction solvents in various fields of chemistry, and various IL-based extraction systems ${ }^{10-16}$ have been developed. Although there are several examples in which ILs are utilized as pretreatment agents for aqueous samples in

$\dagger$ To whom correspondence should be addressed. E-mail: hamamoto@chiba-u.jp (T. H.); katsuta@ faculty.chiba-u.jp (S. K.) toxicant analyses, ${ }^{17-20}$ comparative investigations of different ILs with regard to their extraction efficiency for toxicant analysis have not been conducted systematically. In a previous study, ${ }^{21}$ we investigated in detail the partition behaviors of $[\mathrm{PQ}]^{2+}$ in various IL/water biphasic systems, and found that the $[\mathrm{PQ}]^{2+}$ extractability with ILs is considerably dependent on the IL constituent ions and can be increased using an IL composed of a more hydrophilic cation and a more hydrophobic anion. In addition, the $[\mathrm{PQ}]^{2+}$ extractability was found to be expressed as a function of the aqueous solubility of ILs (the square root of the aqueous solubility product of IL, $K_{\mathrm{sp}}{ }^{1 / 2}$ ). From these findings, we envisaged that the microextraction of $[\mathrm{PQ}]^{2+}$ could be achieved by using an IL such as 1-ethyl-3-methylimidazolium bis(nonafluorobutanesulfonyl)amide ([EMIm] $\left[\mathrm{NNf}_{2}\right]$, Fig. 1), which was designed with a higher hydrophilic cation and a higher hydrophobic anion. Although [EMIm] $\left[\mathrm{NNf}_{2}\right]$ was a known IL reported by Quek et al., ${ }^{22}$ its property as an extractant<smiles>CCn1cc[n+](C)c1</smiles>

[EMIm] $^{+}$<smiles>[13CH3]S(=O)(=O)NS(=O)(=O)C(F)(F)F</smiles>

$\left[\mathrm{NNf}_{2}\right]^{-}$
Fig. 1 Structural formulas of $[\mathrm{EMIm}]^{+}$and $\left[\mathrm{NNf}_{2}\right]^{-}$. 
has not been investigated.

In this study, we have confirmed the high $[\mathrm{PQ}]^{2+}$ extractability with $[\mathrm{EMIm}]\left[\mathrm{NNf}_{2}\right]$ and applied it to a simple and efficient microextraction method for $[\mathrm{PQ}]^{2+}$ and its analogs in water samples prior to HPLC determination. The $[\mathrm{PQ}]^{2+}$ extractability was evaluated by investigating the partition behavior of $[\mathrm{PQ}]^{2+}$ in the $[\mathrm{EMIm}]\left[\mathrm{NNf}_{2}\right] /$ water biphasic system, as previously described. ${ }^{21}$ The microextraction was performed with in situ formation of $[\mathrm{EMIm}]\left[\mathrm{NNf}_{2}\right]$ in the sample solution. This microextraction technique, in which solvent (IL) formation and extraction processes occur simultaneously was first reported by Igarashi and Yotsuyanagi ${ }^{23}$ using tetrabutylammonium perfluorooctanesulfonate, and it is often called "in situ solvent formation microextraction" (ISFME). ${ }^{24}$ The determination of $[\mathrm{PQ}]^{2+}$ concentrated in the IL phase was performed by hydrophilic interaction chromatography (HILIC) with a photodiode array detection (DAD) system. As well as $[\mathrm{PQ}]^{2+}$, $1,1^{\prime}$-ethylene-2,2'-bipyridinium dication (diquat, $[\mathrm{DQ}]^{2+}$ ) and $1,1^{\prime}$-diethyl-4,4'-bipyridinium dication (ethylparaquat, $[\mathrm{EPQ}]^{2+}$; internal standard) were also selected as the targets. Furthermore, the validation of the proposed method and its applicability for real environmental water samples are discussed.

\section{Experimental}

\section{Reagents and materials}

[EMIm]Cl (Tokyo Chemical Industry Co., Tokyo, Japan; $>97 \%$ ) and $\mathrm{Li}\left[\mathrm{NNf}_{2}\right]$ (Wako Pure Chemical Industries, Osaka, Japan; $>97 \%$ ) were used as received. [PQ]Cl ${ }_{2}$ (Tokyo Chemical Industry Co.; $>98.0 \%$ ) was dried at $100^{\circ} \mathrm{C}$ for $3 \mathrm{~h}$ prior to use. [DQ] $\mathrm{Br}_{2}$ (Dr. Ehrenstorfer GmbH, Augsburg, Germany; >99.5\%) and $[\mathrm{EPQ}] \mathrm{I}_{2}$ (Sigma-Aldrich Co., St. Louis, MO; 99\%) were used as received. Water was distilled and further deionized with a Milli-Q Lab system (Millipore, Billerica, MA). Dichloromethane (Kanto Chemical Co., Tokyo, Japan; guaranteed reagent grade) was purified by distillation. Sodium picrate $(\mathrm{Na}[\mathrm{Pic}])$ monohydrate (Kanto Chemical Co.; extra pure grade), formic acid (Wako Pure Chemical Industries; LC/MS grade), ammonium formate (Wako Pure Chemical Industries; guaranteed reagent grade), methanol (Wako Pure Chemical Industries; LC/MS grade), and acetonitrile (Kanto Chemical Co.; LC/MS grade) were used as received. Tap water was collected at our forensic science laboratory. Ground water was collected from a natural well in Chiba City. Lake water samples were collected from Lake Teganuma (Abiko City) and Lake Inbanuma (Sakura City). All water samples were stored in a refrigerator at $4{ }^{\circ} \mathrm{C}$ after being filtered through $0.45 \mu \mathrm{m}$ PVDF membranes.

\section{Apparatus and analytical conditions}

For the characterization of the synthetic $[\mathrm{EMIm}]\left[\mathrm{NNf}_{2}\right]$, an Exactive mass spectrometer (Thermo Fisher Scientific Inc., Waltham, MA) at the Center for Analytical Instrumentation, Chiba University, was used. To check the impurities of [EMIm] $\left[\mathrm{NNf}_{2}\right]$, i.e., $\mathrm{Li}^{+}$and $\mathrm{Cl}^{-}$, a Z-5000 atomic absorption spectrophotometer (Hitachi High-Technologies Co., Tokyo, Japan) and an F-23 potentiometer equipped with a 6560 chloride ion selective electrode (Horiba, Kyoto, Japan) were used, respectively. For the determination of the water content and density of water-saturated [EMIm] [NNf $\mathrm{NN}_{2}$, an AQ-7 Karl Fischer moisture meter (Hiranuma Sangyo Co., Ibaraki, Japan) and a DMA35n oscillating U-tube density meter (Anton Paar GmbH, Graz, Austria) were used, respectively. For the determination of the aqueous solubility of [EMIm] $\left[\mathrm{NNf}_{2}\right]$ and the distribution ratio of $[\mathrm{PQ}]^{2+}$ in the $[\mathrm{EMIm}]\left[\mathrm{NNf}_{2}\right] /$ water biphasic system, a UV-1800 UV/VIS spectrophotometer (Shimadzu Co., Kyoto, Japan) was used.

HILIC analysis was performed using an UltiMate 3000 HPLC system (Thermo Fisher Scientific Inc., Waltham, MA) equipped with a DAD. A ZIC-HILIC column (Merck KGaA, Darmstadt, Germany; $150 \times 2.1 \mathrm{~mm}$, particle size $5 \mu \mathrm{m}$ ) connected with a ZIC-HILIC guard column $(20 \times 2.1 \mathrm{~mm}$, particle size $5 \mu \mathrm{m})$ was used at $40^{\circ} \mathrm{C}$ for the separation. A mixture of methanol and $100 \mathrm{mM}$ ammonium formate buffer adjusted to $\mathrm{pH} 3.5$ with formic acid was used as the mobile phase with a gradient elution at a flow rate of $0.2 \mathrm{~mL} \mathrm{~min}{ }^{-1}$. This separation column and mobile phase were pre-optimized so as to improve the separation of the analytical targets based on the previous report $^{25}$ (Figs. S1 - S3 (Supporting Information)). The volume fraction of methanol in the mobile phase was started at $95 \%$, linearly decreased to $5 \%$ for $0-15 \mathrm{~min}$, and kept at $5 \%$ for $15-20 \mathrm{~min}$. The injection volume of the sample was $10.0 \mu \mathrm{L}$. The wavelength range measured by DAD was set to 190 $800 \mathrm{~nm}$. The target analytes were monitored by absorbances at $256 \mathrm{~nm}\left(\right.$ for $[\mathrm{PQ}]^{2+}$ and $[\mathrm{EPQ}]^{2+}$ ) and $310 \mathrm{~nm}$ (for $[\mathrm{DQ}]^{2+}$ ).

Preparation and physical properties measurements of [EMIm][NNf $\left.f_{2}\right]$

Water-saturated $[\mathrm{EMIm}]\left[\mathrm{NNf}_{2}\right]$ was prepared by mixing aqueous solutions of $[\mathrm{EMIm}] \mathrm{Cl}$ and $\mathrm{Li}\left[\mathrm{NNf}_{2}\right]$ in the molar ratio $1: 1.2$. The IL phase separated from the aqueous phase was washed 10 times with deionized water. The water content and the density of the water-saturated [EMIm] $\left[\mathrm{NNf}_{2}\right]$ were both determined at $25^{\circ} \mathrm{C}$. In addition, the aqueous solubility of $[\mathrm{EMIm}]\left[\mathrm{NNf}_{2}\right]$ was determined by measuring the cation concentration in the [EMIm] $\left[\mathrm{NNf}_{2}\right]$-saturated aqueous solution at $25^{\circ} \mathrm{C}$ by the ion pair extraction-spectrophotometric method using dichloromethane as extracting solvent and $\mathrm{Na}[\mathrm{Pic}]$ as ionpairing agent; $\lambda_{\max }=367.8 \mathrm{~nm}, \varepsilon=1.43 \times 10^{4} \mathrm{~cm}^{-1} \mathrm{M}^{-1}$ for [EMIm] $[\mathrm{Pic}]$ in dichloromethane. ${ }^{21}$

\section{Partition experiments}

Five milliliters of an aqueous solution of $[\mathrm{PQ}] \mathrm{Cl}_{2}\left(1.2 \times 10^{-3}\right.$ to $2.5 \times 10^{-2} \mathrm{M}$ ) and $0.2 \mathrm{~mL}$ of water-saturated [EMIm] $\left[\mathrm{NNf}_{2}\right]$ were placed in a 50-mL round-bottom centrifuge tube made of polypropylene (PP). The volume of the water-saturated [EMIm] $\left[\mathrm{NNf}_{2}\right]$ was accurately calculated from the mass by using the density. Then, the biphasic mixture in the centrifuge tube was equilibrated by stirring with a magnetic stirrer for $1 \mathrm{~h}$ in a thermostatic water bath at $25.0^{\circ} \mathrm{C}$. After the two phases were completely separated by centrifugation for $5 \mathrm{~min}$ at $1500 \times g$, the tube was allowed to stand for $15 \mathrm{~min}$ in the thermostatic water bath. The concentration of $[\mathrm{PQ}]^{2+}$ in the aqueous phase was determined spectrophotometrically; $\lambda_{\max }=256.0 \mathrm{~nm}, \varepsilon=$ $2.05 \times 10^{4} \mathrm{~cm}^{-1} \mathrm{M}^{-1} .{ }^{21}$ The concentration of $[\mathrm{PQ}]^{2+}$ in the IL phase was calculated from the mass balance, where the volume change of the IL phase due to its dissolution into the aqueous phase was taken into account on the basis of the aqueous solubility of $[\mathrm{EMIm}]\left[\mathrm{NNf}_{2}\right]$. The distribution ratio $(D)$ was calculated as the ratio of the molar concentration in the IL phase to that in the aqueous phase

\section{[EMIm] [NNf $\left.f_{2}\right]$-ISFME procedure}

First, $10 \mathrm{~mL}$ of $4.9 \times 10^{-4} \mathrm{M}$ aqueous [PQ]Cl${ }_{2}$ solution was placed in a $50-\mathrm{mL}$ conical-bottom $\mathrm{PP}$ centrifuge tube, into which $0.2 \mathrm{~mL}$ of $1.2 \times 10^{-1} \mathrm{M}$ aqueous [EMIm] Cl solution was mixed thoroughly. Then, $1.0 \mathrm{~mL}$ of $2.3 \times 10^{-2} \mathrm{M}$ aqueous $\mathrm{Li}\left[\mathrm{NNf}_{2}\right]$ solution was added using a pipette at room temperature, which resulted in the formation of a cloudy solution of 


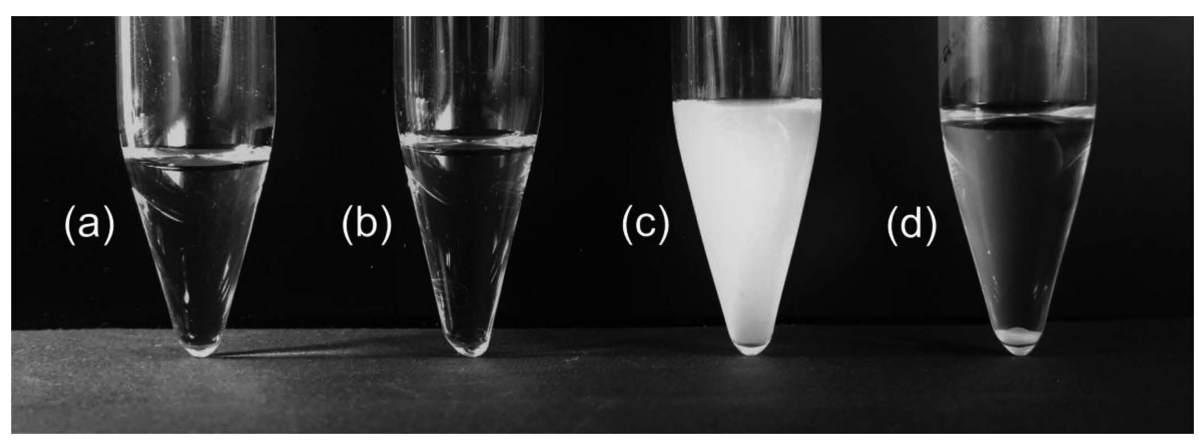

Fig. 2 Images of the different steps in ISFME: (a) the initial sample solution (pure water), (b) after adding aqueous $[\mathrm{EMIm}] \mathrm{Cl}$ solution and mixing, (c) immediately after adding aqueous $\mathrm{Li}\left[\mathrm{NNf}_{2}\right]$ solution, and (d) after ultrasonication and centrifugation. For easy viewing, the volumes of the initial sample solution and the added solutions were made smaller than those used in the actual ISFME experiments, although the amounts of the added IL reagents were the same.

[EMIm] $\left[\mathrm{NNf}_{2}\right]$. The volume of the $[\mathrm{EMIm}]\left[\mathrm{NNf}_{2}\right]$ product was calculated at $9.5 \mu \mathrm{L}$ in the water-saturated state, $0.1 \mu \mathrm{L}$ of which was estimated to have dissolved in the aqueous phase on the basis of its solubility. Consequently, the ratio of the volume of the IL phase to that of the initial aqueous phase was established as $1.1 \times 10^{3}\left(=1.0 \times 10^{4} / 9.4\right)$. In the case that the cloudy solution was immediately centrifuged, the IL phase often became solidified. Since the ultrasonication of the cloudy solution was effective in preventing the solidification of the IL phase, ultrasonication $(26 \mathrm{kHz}, 150 \mathrm{~W})$ for $10 \mathrm{~min}$ was conducted to fluidify the IL phase, followed by complete separation of the two phases by centrifugation for $5 \mathrm{~min}$ at $1500 \times g$. The aqueous concentration of $[\mathrm{PQ}]^{2+}$ was determined spectrophotometrically, and then the $D$ value was calculated as described previously. Photographs of these ISFME steps are shown in Fig. 2. In order to confirm that the extraction using the ISFME method has reached equilibrium, batch partition experiments under the same volume conditions were also conducted with stirring for $10-360 \mathrm{~min}$.

\section{HILIC analysis of water samples}

First, $10 \mathrm{~mL}$ of a working aqueous solution of $[\mathrm{PQ}]^{2+}$ and $[\mathrm{DQ}]^{2+}\left(0.5-50 \mathrm{ng} \mathrm{mL}^{-1}\right.$; nearly $\left.3 \times 10^{-9}-3 \times 10^{-7} \mathrm{M}\right)$ or a real environmental water sample spiked with these analytes at $5 \mathrm{ng} \mathrm{mL}^{-1}$ was placed in a $50-\mathrm{mL}$ conical PP tube. Then, $0.2 \mathrm{~mL}$ of $500 \mathrm{ng} \mathrm{mL}^{-1}$ aqueous [EPQ] ${ }^{2+}$ solution was added as internal standard. After [EMIm] $\left[\mathrm{NNf}_{2}\right]$-ISFME was conducted as described above, the aqueous phase was removed to obtain the IL precipitate. The HILIC sample was prepared by adding $100 \mu \mathrm{L}$ methanol to the IL precipitate, followed by transferring the solution to a PP autosampler vial and injecting $10 \mu \mathrm{L}$ into the HPLC system. Three replicate extractions for each working solution and five replicate extractions for each water sample were performed with determination.

To evaluate the proposed method, the linearity, repeatability, and sensitivity were examined from the chromatograms obtained from the working solutions. The calibration lines for the spiked analytes were obtained by applying the linear least-squares method to the plots of the peak area ratios to internal standard against the spiked concentrations. The detection limits were calculated from the concentration of the analytes, whose peak height was three times the baseline noise (signal-to-noise ratio $(S / N)=3)$. In addition, the quantification accuracy and precision were examined from the chromatograms obtained from the water samples. The accuracy was estimated as the relative errors (REs) between the found concentration values calculated from the calibration lines and the spiked ones $\left(5 \mathrm{ng} \mathrm{mL}^{-1}\right)$. The precision was estimated as relative standard deviations (RSDs) of the found concentration values in five replicates. Furthermore, the extraction recovery was also examined by analyzing two groups of the water samples that had been spiked with the analytes at $5 \mathrm{ng} \mathrm{mL}^{-1}$, one before ISFME and another after ISFME. The internal standard $\left([\mathrm{EPQ}]^{2+}, 100 \mathrm{ng}\right)$ was added to each sample after ISFME. Five replicate extractions for each water sample were performed on the group before ISFME.

\section{Results and Discussion}

\section{Characterization of [EMIm] $\left[\mathrm{NNf}_{2}\right]$}

Water-saturated [EMIm] $\left[\mathrm{NNf}_{2}\right]$ was obtained in almost quantitative yield (94\%). In the electrospray ionization-mass spectrometric measurement of the acetonitrile solution of the product, an ion with $\mathrm{m} / \mathrm{z} 111.0915$ ([EMIm] $]^{+}$, calculated for $\mathrm{C}_{6} \mathrm{H}_{11} \mathrm{~N}_{2}$ : 111.0922) and another with $\mathrm{m} / z$, $579.8991\left(\left[\mathrm{NNf}_{2}\right]^{-}\right.$, calculated for $\mathrm{C}_{8} \mathrm{NO}_{4} \mathrm{~F}_{18} \mathrm{~S}_{2}$ : 579.8981) were confirmed by positive ion mode and negative ion mode, respectively. The mass fractions of $\mathrm{Li}^{+}$and $\mathrm{Cl}^{-}$in the product were less than $2 \times 10^{-7}$ and $2 \times 10^{-6}$, respectively. The values of the water content and density of water-saturated $[\mathrm{EMIm}]\left[\mathrm{NNf}_{2}\right]$ were determined to be $0.45 \pm 0.03 \mathrm{wt} \%\left(25 \pm 1{ }^{\circ} \mathrm{C}\right)$ and $1.6815 \pm$ $0.0001 \mathrm{~g} \mathrm{~mL}^{-1}\left(25.0 \pm 0.2^{\circ} \mathrm{C}\right)$, respectively. In addition, the value of the aqueous solubility of $[\mathrm{EMIm}]\left[\mathrm{NNf}_{2}\right]$ was $(2.33 \pm$ $0.03) \times 10^{-5} \mathrm{M}\left(25.0 \pm 0.2^{\circ} \mathrm{C}\right)$; the aqueous solubility product, $K_{\text {sp }}$, was consequently calculated as $5.43 \times 10^{-10} \mathrm{M}^{2}$. Because of the high hydrophobicity and density, [EMIm] $\left[\mathrm{NNf}_{2}\right]$ is easily separable from the aqueous phase by centrifugation and suitable as a microextraction medium for water samples.

\section{Evaluation of $[\mathrm{PQ}]^{2+}$ extractability with [EMIm] $\left[\mathrm{NNf}_{2}\right]$}

In our previous study, ${ }^{21}$ an equilibrium theory about the extraction of a target $n$-valent cation $\left(\mathrm{T}^{\mathrm{n}+}\right)$ in an IL/water biphasic system was established. On this basis, the following equations hold for the $D$ value of $[\mathrm{PQ}]^{2+}\left([\mathrm{PQ}]^{2+}=\mathrm{T}^{2+}\right)$.

$$
\begin{aligned}
& \log D=\log K_{\text {ex-IE }}-2 \log \left\{\Delta\left[\mathrm{T}^{2+}\right]_{\mathrm{W}}+\left(\Delta\left[\mathrm{T}^{2+}\right]_{\mathrm{w}}+K_{\mathrm{sp}}\right)^{1 / 2}\right\} \\
& \log D=\log K_{\text {ex-IP }}+2 \log \left\{-\Delta\left[\mathrm{T}^{2+}\right]_{\mathrm{w}}+\left(\Delta\left[\mathrm{T}^{2+}\right]_{\mathrm{w}}+K_{\mathrm{sp}}\right)^{1 / 2}\right\}
\end{aligned}
$$


Table 1 Aqueous equilibrium concentrations and distribution ratios of $[\mathrm{PQ}]^{2+}\left(\mathrm{T}^{2+}\right)$ in $[\mathrm{EMIm}]\left[\mathrm{NNf}_{2}\right] /$ water system ${ }^{\mathrm{a}}$ at $25.0^{\circ} \mathrm{C}$

\begin{tabular}{ccccc}
\hline No. & {$\left[\mathrm{T}^{2+}\right]_{\mathrm{W}, \text { Init }} \mathrm{b} / \mathrm{mM}$} & {$\left[\mathrm{T}^{2+}\right]_{\mathrm{W}} / \mathrm{mM}$} & $\Delta\left[\mathrm{T}^{2+}\right]_{\mathrm{W}} / \mathrm{mM}$ & $D$ \\
\hline 1 & 1.23 & 0.00548 & 1.23 & $5.61 \times 10^{3}$ \\
2 & 2.47 & 0.0216 & 2.45 & $2.84 \times 10^{3}$ \\
3 & 4.93 & 0.152 & 4.78 & $7.85 \times 10^{2}$ \\
4 & 12.3 & 2.00 & 10.3 & $1.29 \times 10^{2}$ \\
5 & 24.7 & 10.3 & 14.4 & $3.51 \times 10^{1}$ \\
\hline
\end{tabular}

a. The volume ratio of the IL phase to the aqueous phase is $1 / 25$.

b. Initial concentration of $[\mathrm{PQ}] \mathrm{Cl}_{2}$ in the aqueous phase.

Here, $K_{\text {ex-IE }}$ and $K_{\text {ex-IP }}$ are the equilibrium constants for two types of extraction reactions of $\mathrm{T}^{2+}$, i.e., the ion exchange extraction with IL cations in the IL phase and the ion pair extraction with IL anions in the aqueous phase, respectively. $\Delta\left[\mathrm{T}^{2+}\right]_{\mathrm{W}}$ is the difference between the initial and the equilibrium concentrations of $\mathrm{T}^{2+}$ in the aqueous phase, which corresponds to the extracted amount of $\mathrm{T}^{2+} . K_{\mathrm{sp}}$ is the aqueous solubility product of IL. The values of $K_{\text {ex-IE }}, K_{\text {ex-IP, }}$ and $K_{\text {sp }}$ are all dependent on the specific IL. In fact, Eqs. (1) and (2) are essentially equal to each other, because the following relationship holds between $K_{\text {ex-IE }}$ and $K_{\text {ex-IP }}: K_{\text {ex-IE }} / K_{\text {ex-IP }}=K_{\text {sp }}^{2}$.

According to Eqs. (1) and (2), when $\Delta\left[\mathrm{T}^{2+}\right]_{\mathrm{W}} \rightarrow 0$ (in the dilute condition of $\left.\mathrm{T}^{2+}\right)$, the $\log D$ value $\left(\log D_{0}\right)$ is expressed as follows:

$$
\begin{aligned}
& \log D_{0}=\log K_{\text {ex-IE }}-2 \log K_{\text {sp }}^{1 / 2} \\
& \log D_{0}=\log K_{\text {ex-IP }}+2 \log K_{\text {sp }}^{1 / 2}
\end{aligned}
$$

Equations (3) and (4) indicate that the $\log D$ value becomes constant regardless of $\Delta\left[\mathrm{T}^{2+}\right]_{\mathrm{W}}$ in the dilute condition. The $D_{0}$ value is the upper limit of $D$ that can be attained in a certain IL/water system, and thus it can be used to compare the extractability of different ILs for a given target cation.

The aqueous equilibrium concentrations of $[\mathrm{PQ}]^{2+}\left(\left[\mathrm{T}^{2+}\right]_{\mathrm{W}}\right)$ and the $D$ values in the $[\mathrm{EMIm}]\left[\mathrm{NNf}_{2}\right] /$ water system obtained at different initial concentrations $\left(\left[\mathrm{T}^{2+}\right]_{\mathrm{W}, \text { Init }}\right)$ are shown in Table 1, together with the values of $\Delta\left[\mathrm{T}^{2+}\right]_{\mathrm{W}}$ calculated as $\left[\mathrm{T}^{2+}\right]_{\mathrm{W}, \text { Init }}-$ $\left[\mathrm{T}^{2+}\right]_{\mathrm{W}}$. In addition, the logarithmic values of $D$ are plotted against those of $\Delta\left[\mathrm{T}^{2+}\right]_{\mathrm{w}}$ in Fig. 3. The solid line in Fig. 3 is the regression curve calculated from Eqs. (1) or (2) using the $K_{\mathrm{sp}}$ value of $[\mathrm{EMIm}]\left[\mathrm{NNf}_{2}\right]\left(5.43 \times 10^{-10} \mathrm{M}^{2}\right)$. As can be seen, the $D$ value of $[\mathrm{PQ}]^{2+}$ increases as the $[\mathrm{PQ}]^{2+}$ concentration decreases, reaching its upper limit at $D \approx 10^{8}$. At this point, the recovery of $[\mathrm{PQ}]^{2+}$ is $99 \%$ for a volume ratio IL phase to the aqueous phase of $1 / 10^{6}$, indicating that a $10^{6}$-fold enrichment of $[\mathrm{PQ}]^{2+}$ can be achieved using $[\mathrm{EMIm}]\left[\mathrm{NNf}_{2}\right]$. Therefore, $[\mathrm{EMIm}]\left[\mathrm{NNf}_{2}\right]$ can be envisaged as a powerful microextraction medium for trace $[\mathrm{PQ}]^{2+}$ in water samples.

From the data in Table 1 , the $K_{\text {ex-IE }}$ and $K_{\text {ex-IP }}$ values were determined using Eqs. (1) and (2), respectively. The $D_{0}$ value was also calculated from Eqs. (3) or (4). The logarithmic values of $K_{\text {ex-IE }}, K_{\text {ex-IP }}$, and $D_{0}$ are summarized in Table 2, together with the literature values of 1-ethyl-3-methylimidazolium bis(trifluoromethanesulfonyl)amide ([EMIm] $\left.\left[\mathrm{NTf}_{2}\right]\right)$ and 1-butyl-3methylimidazolium bis(nonafluorobutanesulfonyl)amide ([BMIm]$\left.\left[\mathrm{NNf}_{2}\right]\right)$, whose cation or anion is common with [EMIm] $\left[\mathrm{NNf}_{2}\right]$ respectively. ${ }^{21}$ The $D_{0}$ value of $[\mathrm{PQ}]^{2+}$ with $[\mathrm{EMIm}]\left[\mathrm{NNf}_{2}\right]$ was found to be $9.79 \times 10^{7}\left(\log D_{0}=7.991\right)$, which is 22 times higher than the $D_{0}$ value with [BMIm] $\left[\mathrm{NNf}_{2}\right.$ ] (the highest one in Ref. 21). When comparing the $\log K_{\text {ex-IE }}$ and $\log K_{\text {ex-IP }}$ values

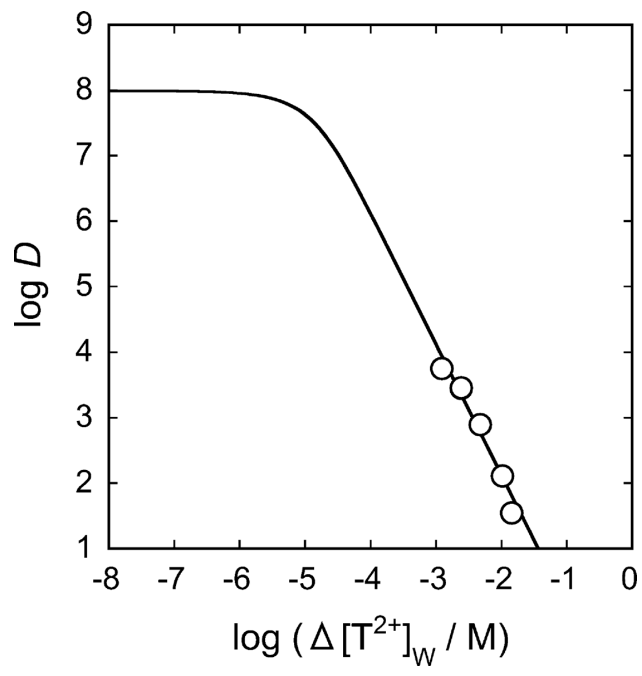

Fig. 3 Distribution ratio of $[\mathrm{PQ}]^{2+}$ as a function of the difference between the initial and equilibrium concentrations of $[\mathrm{PQ}]^{2+}$ in the aqueous phase for the $[\mathrm{EMIm}]\left[\mathrm{NNf}_{2}\right]$ /water biphasic system. The solid line is the regression curve based on Eqs. (1) or (2).

Table 2 Distribution ratios $\left(D_{0}\right)$ of $[\mathrm{PQ}]_{2+}$ in dilute condition ${ }^{\mathrm{a}}$ and extraction equilibrium constants $\left(K_{\text {ex-IE }}\right.$ and $\left.K_{\text {ex-IP }}\right)$ in

\begin{tabular}{|c|c|c|c|}
\hline IL & $\log \left(K_{\text {ex-IE }} / \mathrm{M}^{2}\right)$ & $\log \left(K_{\text {ex-IP }} / \mathrm{M}^{-2}\right)$ & $\log D_{0}$ \\
\hline$[\mathrm{EMIm}]\left[\mathrm{NNf}_{2}\right]$ & $-1.274(0.061)^{\mathrm{b}}$ & $17.256(0.061)^{b}$ & 7.991 \\
\hline$[\mathrm{EMIm}]\left[\mathrm{NTf}_{2}\right]^{\mathrm{c}}$ & -0.089 & 5.244 & 2.578 \\
\hline$[\mathrm{BMIm}]\left[\mathrm{NNf}_{2}\right]^{\mathrm{c}}$ & -3.086 & 16.373 & 6.643 \\
\hline
\end{tabular}
$[\mathrm{EMIm}]\left[\mathrm{NNf}_{2}\right] /$ water system at $25.0^{\circ} \mathrm{C}$

a. In the condition that $\Delta\left[[\mathrm{PQ}]^{2+}\right]_{\mathrm{W}} \rightarrow 0$.

b. Values in parentheses are standard errors.

c. Ref. 21.

among the three ILs, the difference of the $\log K_{\text {ex-IP }}$ values between [EMIm] $\left[\mathrm{NNf}_{2}\right]$ and $[\mathrm{EMIm}]\left[\mathrm{NTf}_{2}\right]$ stands out as particularly large, which suggests that the high extraction capability of $[\mathrm{EMIm}]\left[\mathrm{NNf}_{2}\right]$ for $[\mathrm{PQ}]^{2+}$ stems most likely from the contribution of the ion pair extraction with $\left[\mathrm{NNf}_{2}\right]^{-}$. In addition, the density and the aqueous solubility of [EMIm] $\left[\mathrm{NNf}_{2}\right]$ are not so different from those of [BMIm] [NNf $\mathrm{N}_{2}$ : density, $1.6815 \mathrm{~g} \mathrm{~mL}^{-1}$ for $[\mathrm{EMIm}]\left[\mathrm{NNf}_{2}\right]$ (wet) and $1.6111 \mathrm{~g} \mathrm{~mL}^{-1}$ for $[\mathrm{BMIm}]\left[\mathrm{NNf}_{2}\right](\mathrm{dry}){ }^{26}$ aqueous solubility, $2.33 \times 10^{-5} \mathrm{M}$ for $[\mathrm{EMIm}]\left[\mathrm{NNf}_{2}\right]$ and $1.366 \times 10^{-5} \mathrm{M}$ for $[\mathrm{BMIm}]\left[\mathrm{NNf}_{2}\right]{ }^{21}$

\section{Extraction behavior of $[\mathrm{PQ}]^{2+}$ by $[E M I m]\left[\mathrm{NNf}_{2}\right]-I S F M E$}

In Fig. 4, the stirring time dependence of the $D$ value of $[\mathrm{PQ}]^{2+}$ by the batch extraction method with stirring is shown, where the $D$ value obtained by the ISFME method is indicated with a broken line for comparison. In the stirring extraction, the $D$ value increases with the stirring time, becoming constant after $3 \mathrm{~h}$ or more of stirring; the $D$ value at equilibrium is consistent with that obtained in the ISFME method, which indicates that the extraction equilibrium is also attained using the ISFME method. Interestingly, the net extraction time in the ISFME method is only $10 \mathrm{~min}$ for ultrasonication, which is much shorter than that required when using the stirring method. 


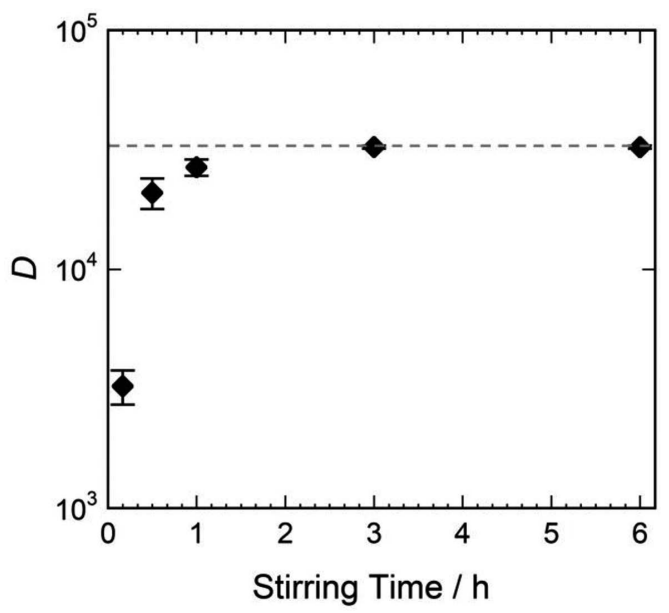

Fig. 4 Distribution ratio of $[\mathrm{PQ}]^{2+}$ as a function of stirring time in batch extraction method with stirring. The broken line shows the distribution ratio in ISFME method.

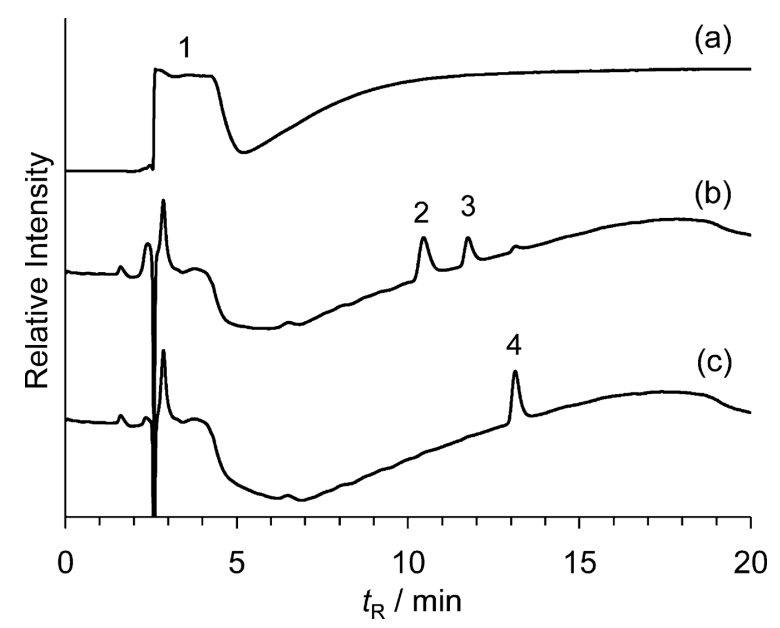

Fig. 5 Representative chromatograms obtained from [EMIm] $\left[\mathrm{NNf}_{2}\right]-$ ISFME-HILIC analysis of a working aqueous solution at $5 \mathrm{ng} \mathrm{mL}^{-1}$. Monitoring wavelength: (a) $210 \mathrm{~nm}$; (b) $256 \mathrm{~nm}$; (c) $310 \mathrm{~nm}$. 1: $[\mathrm{EMIm}]\left[\mathrm{NNf}_{2}\right] ; 2:[\mathrm{EPQ}]^{2+} ; 3:[\mathrm{PQ}]^{2+} ; 4:[\mathrm{DQ}]^{2+}$.

Determination of $[P Q]^{2+}$ in water samples by $[\mathrm{EMIm}]\left[\mathrm{NNf}_{2}\right]-$ ISFME-HILIC analysis

In Fig. 5, representative chromatograms obtained from the working aqueous solution spiked with $[\mathrm{PQ}]^{2+}$ and $[\mathrm{DQ}]^{2+}$ at $5 \mathrm{ng} \mathrm{mL}^{-1}$ are shown. In the top chromatogram (Fig. 5(a)), which was obtained by monitoring the absorbance at $210 \mathrm{~nm}$ corresponding to a light absorption of [EMIm] $\left[\mathrm{NNf}_{2}\right]$, a peak of [EMIm] $\left[\mathrm{NNf}_{2}\right]$ can be seen around 4 min of retention time $\left(t_{\mathrm{R}}\right)$, implying that $[\mathrm{EMIm}]\left[\mathrm{NNf}_{2}\right]$ is hardly retained in the ZICHILIC column. On the other hand, in the middle and bottom chromatograms (Figs. 5(b) and 5(c)), which were obtained by monitoring the absorbances at 256 and $310 \mathrm{~nm}$, respectively, $[\mathrm{PQ}]^{2+},[\mathrm{DQ}]^{2+}$, and $[\mathrm{EPQ}]^{2+}$ (internal standard) were detected separately around $t_{\mathrm{R}}=10-14 \mathrm{~min}$.

Using the chromatograms obtained from the working solutions, the [EMIm] [NNf $\left.\mathrm{NN}_{2}\right]$-ISFME method combined with HILIC was validated in terms of linearity and sensitivity (Table 3 and Fig. S4 (Supporting Information)). Both $[\mathrm{PQ}]^{2+}$
Table 3 Performance characteristics of the [EMIm] $\left[\mathrm{NNf}_{2}\right]-$ ISFME method combined with HILIC for pure water

\begin{tabular}{cccccc}
\hline Analyte & $\begin{array}{c}\text { Linear } \\
\text { equation }\end{array}$ & $\begin{array}{c}\text { Linearity } \\
\text { range/ } \\
\mathrm{ng} \mathrm{mL} \mathrm{mL}^{-1}\end{array}$ & $\begin{array}{c}\text { Correlation } \\
\text { coefficient } \\
\left(R^{2}\right)\end{array}$ & $\begin{array}{c}\text { Precision } \\
(\mathrm{RSD}), \%\end{array}$ & $\begin{array}{c}\text { Detection } \\
\text { limit/ } \\
\mathrm{ng} \mathrm{mL}^{-1}\end{array}$ \\
\hline$[\mathrm{PQ}]^{2+}$ & $Y=0.1028 X$ \\
-0.0069 & $1-50$ & 0.9999 & $<2.85$ & 0.16 \\
{$[\mathrm{DQ}]^{2+} \begin{array}{c}Y=0.1100 X \\
-0.0023\end{array}$} & $0.5-50$ & 0.9999 & $<3.56$ & 0.15 \\
\hline
\end{tabular}

a. Based on three replicates perfomed for every concentration.

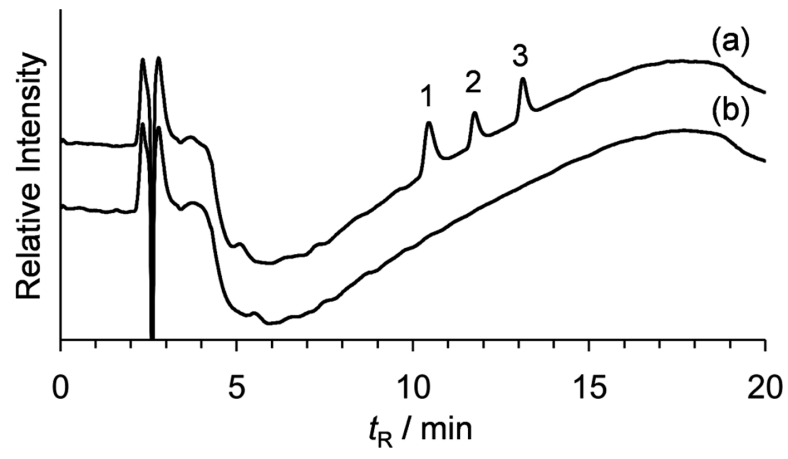

Fig. 6 Representative chromatograms obtained from [EMIm] $\left[\mathrm{NNf}_{2}\right]-$ ISFME-HILIC analysis of Lake Inbanuma water sample. For simplifying the figure, the summed chromatograms of 256 and $310 \mathrm{~nm}$ are shown. (a): Spiked with $[\mathrm{PQ}]^{2+}$ and $[\mathrm{DQ}]^{2+}$ at $5 \mathrm{ng} \mathrm{mL}^{-1}$; (b): blank. 1: $[\mathrm{EPQ}]^{2+} ; 2:[\mathrm{PQ}]^{2+} ; 3:[\mathrm{DQ}]^{2+}$.

Table 4 Analytical performance of the [EMIm] $\left.\mathrm{NNf}_{2}\right]$-ISFME method combined with HILIC for real environmental water samples spiked at $5 \mathrm{ng} \mathrm{mL}^{-1}$

\begin{tabular}{llccc}
\hline \multicolumn{1}{c}{ Sample } & Analyte & $\begin{array}{c}\text { Accuracy }^{\mathrm{a}} \\
(\mathrm{RE}), \%\end{array}$ & $\begin{array}{c}\text { Precision }^{\mathrm{a}} \\
(\mathrm{RSD}), \%\end{array}$ & $\begin{array}{c}\text { Recovery } \\
\%\end{array}$ \\
\hline \multirow{2}{*}{ Tap } & {$[\mathrm{PQ}]^{2+}$} & +1.07 & 0.81 & $102.1 \pm 1.9$ \\
\multirow{3}{*}{ Ground } & {$[\mathrm{DQ}]^{2+}$} & -0.19 & 0.71 & $104.3 \pm 1.7$ \\
& {$[\mathrm{PQ}]^{2+}$} & +0.51 & 0.58 & $100.8 \pm 2.1$ \\
Lake Teganuma & {$[\mathrm{DQ}]^{2+}$} & +0.25 & 1.68 & $103.3 \pm 1.2$ \\
& {$[\mathrm{PQ}]^{2+}$} & +0.47 & 0.90 & $101.5 \pm 0.7$ \\
Lake Inbanuma & {$[\mathrm{DQ}]^{2+}$} & -0.66 & 0.40 & $104.9 \pm 1.2$ \\
& {$[\mathrm{PQ}]^{2+}$} & -0.57 & 0.99 & $100.8 \pm 0.9$ \\
& {$[\mathrm{DQ}]^{2+}$} & -3.22 & 2.06 & $103.9 \pm 0.3$ \\
\hline
\end{tabular}

a. Based on five replicates performed for every water sample.

and $[\mathrm{DQ}]^{2+}$ exhibited good linearity with correlation coefficients of 0.9999 in wide concentration ranges $(1-50$ and 0.5 $50 \mathrm{ng} \mathrm{mL}^{-1}$, respectively). The RSDs of peak area ratios of $[\mathrm{PQ}]^{2+}$ and $[\mathrm{DQ}]^{2+}$, calculated in triplicate for each concentration, were less than 2.85 and $3.56 \%$, respectively. In addition, the detection limits of $[\mathrm{PQ}]^{2+}$ and $[\mathrm{DQ}]^{2+}$ were determined as 0.16 and $0.15 \mathrm{ng} \mathrm{mL}^{-1}$, respectively.

Once validated, the present method was applied to the analysis of four real environmental water samples spiked with $[\mathrm{PQ}]^{2+}$ and $[D Q]^{2+}$ at $5 \mathrm{ng} \mathrm{mL}^{-1}$. The typical chromatograms acquired after [EMIm] [NNf $\mathrm{NN}_{2}$-ISFME was performed on these samples are shown in Figs. 6 and S5 (Supporting Information). For simplifying the figure, each chromatogram is shown as the 
summation of the chromatograms of 256 and $310 \mathrm{~nm}$, though the analytical performances were evaluated from each single wavelength chromatogram. $[\mathrm{PQ}]^{2+},[\mathrm{DQ}]^{2+}$, and $[\mathrm{EPQ}]^{2+}$ (internal standard) were successfully detected without interference from the matrix in each water sample. Table 4 shows the analytical performances of the proposed method for real environmental water samples. In all water samples, the REs and RSDs were less than 3.22 and $2.06 \%$, respectively, with the recoveries in the range of $100.8-104.9 \%$.

Taken together, these results reveal that the $[\mathrm{EMIm}]\left[\mathrm{NNf}_{2}\right]-$ ISFME method combined with HILIC has strong potential for the trace analysis of $[\mathrm{PQ}]^{2+}$ and $[\mathrm{DQ}]^{2+}$ in water samples.

\section{Conclusions}

The ionic liquid [EMIm] $\left[\mathrm{NNf}_{2}\right]$ has been applied to the microextraction and chromatographic analysis of trace $[\mathrm{PQ}]^{2+}$ and $[D Q]^{2+}$ in water samples. From the regression analysis for the relationship between the distribution ratios of $[\mathrm{PQ}]^{2+}$ and its aqueous concentration changes in the extraction from water to $[\mathrm{EMIm}]\left[\mathrm{NNf}_{2}\right]$, the $[\mathrm{PQ}]^{2+}$ extractability with $[\mathrm{EMIm}]\left[\mathrm{NNf}_{2}\right]$ was demonstrated to be extremely high $\left(D \approx 10^{8}\right)$, indicating that $[\mathrm{EMIm}]\left[\mathrm{NNf}_{2}\right]$ was a suitable extractant for the ultra-high preconcentration of trace $[\mathrm{PQ}]^{2+}$ in water samples. In addition, a simple and rapid ISFME procedure with $[\mathrm{EMIm}]\left[\mathrm{NNf}_{2}\right]$, in which aqueous solutions of [EMIm] Cl and $\mathrm{Li}\left[\mathrm{NNf}_{2}\right]$ were added to water samples, was developed. By using an analytical technique that combines [EMIm] $\left[\mathrm{NNf}_{2}\right]$-ISFME with hydrophilic interaction chromatography, the determination of trace $[\mathrm{PQ}]^{2+}$ and $[\mathrm{DQ}]^{2+}$ at the ppb level in water samples could be conducted. The findings in this study may prove useful for the design of new ILs suitable for the microextraction of a variety of cationic toxicants in water samples.

\section{Acknowledgements}

The authors thank Ms. Miho Okai (Graduate School of Science, Chiba University) for her support concerning the measurements of the density and solubility of $[\mathrm{EMIm}]\left[\mathrm{NNf}_{2}\right]$. The authors also thank Mr. T. Nakamura (Graduate School of Science and Engineering, Chiba University) and Ms. S. Kado (Center for Analytical Instrumentation, Chiba University) for their support in MS analysis of [EMIm] $\left[\mathrm{NNf}_{2}\right]$. This research was financially supported by the Japan Society for the Promotion of Science (JSPS) KAKENHI [Grant numbers JP26410145, JP15H00304, JP16H00316].

\section{Supporting Information}

Details showing the optimization of HILIC conditions, calibration curves of $[\mathrm{PQ}]^{2+}$ and $[\mathrm{DQ}]^{2+}$ in water, and representative chromatograms obtained from [EMIm] $\left[\mathrm{NNf}_{2}\right]-$ ISFME-HILIC analysis. This material is available free of charge on the Web at http://www.jsac.or.jp/analsci/.

\section{References}

1. T. J. Haley, Clin. Toxicol., 1979, 14, 1.

2. P. N. Moreira, P. G. Pinho, M. T. Baltazar, M. L. Bastos, F. Carvalho, and R. J. Dinis-Oliveira, Biomed. Chromatogr, 2012, 26, 338.

3. S. K. Baeck, Y. S. Shin, H. S. Chung, and M. Y. Pyo, Arch. Pharmacal Res., 2007, 30, 235.

4. R. D. Whitehead Jr., M. A. Montesano, N. K. Jayatilaka, B. Buckley, B. Winnik, L. L. Needham, and D. B. Barr, J. Chromatogr. B, 2010, 878, 2548.

5. X. L. Ruan, J. J. Qiu, C. Wu, T. Huang, R. B. Meng, and Y. Q. Lai, J. Chromatogr. B, 2014, 965, 85.

6. J. A. Oh, J. B. Lee, S. H. Lee, and H. S. Shin, J. Sep. Sci., 2014, 37, 2900.

7. M. S. F. Santos, L. M. Madeira, and A. Alves, J. Liq. Chromatogr. Relat. Technol., 2015, 38, 472.

8. F. Latifeh, Y. Yamini, and S. Seidi, Environ. Sci. Pollut. Res., 2016, 23, 4411.

9. L. Gao, J. Liu, H. Yuan, and X. Deng, Chromatographia, 2015, 78, 125 .

10. K. D. Clark, O. Nacham, J. A. Purslow, S. A. Pierson, and J. L. Anderson, Anal. Chim. Acta, 2016, 934, 9.

11. G. Bapat, C. Labade, A. Chaudhari, and S. Zinjarde, $A d v$. Colloid Interface Sci., 2016, 237, 1.

12. S. Kimura, Y. Shimizu, A. Eguchi, and N. Hirayama, Solvent Extr. Res. Dev., Jpn., 2016, 23, 145.

13. Y. Kudo, M. Shibata, S. Nomura, and N. Ogawa, Anal. Sci., 2017, 33, 739.

14. A. Eguchi, K. Morita, and N. Hirayama, Anal. Sci., 2017, 33, 1447.

15. T. Mizuta, K. Maeno, K. Sueyoshi, T. Endo, and H. Hisamoto, Anal. Sci., 2018, 34, 517.

16. M. Toita, K. Morita, and N. Hirayama, Anal. Sci., 2018, 34, 1063.

17. Q. Zhou, H. Bai, G. Xie, and J. Xiao, J. Chromatogr. A, 2008, 1188, 148

18. M. Baghdadi and F. Shemirani, Anal. Chim. Acta, 2008, $613,56$.

19. M. M. P. Vázquez, P. P. Vázquez, M. M. Galera, M. D. G. García, and A. Uclés, J. Chromatogr. A, 2013, 1291, 19.

20. C. Toledo-Neira and A. Álvarez-Lueje, Talanta, 2015, 134, 619.

21. T. Hamamoto, M. Okai, and S. Katsuta, J. Phys. Chem. B, 2015, 119, 6317.

22. S. K. Quek, I. M. Lyapkalo, and H. V. Huynh, Tetrahedron, 2006, 62, 3137.

23. S. Igarashi and T. Yotsuyanagi, in Solvent Extraction 1990: Proceedings of the International Solvent Extraction Conference (ISEC '90), ed. T. Sekine and S. Kusakabe, 1992, Elsevier, Amsterdam, 1725 - 1730.

24. M. Baghdadi and F. Shemirani, Anal. Chim. Acta, 2009, 634, 186.

25. Y. Suzuki, T. Kaneko, and K. Saito, Forensic Toxicol., 2018, $36,458$.

26. S. Seki, S. Tsuzuki, K. Hayamizu, Y. Umebayashi, N. Serizawa, K. Takei, and H. Miyashiro, J. Chem. Eng. Data, 2012, 57, 2211. 